\title{
Tecnologias digitais na educação: tecendo novas experiências formativas com professores da educação básica ${ }^{1}$
}

\section{Digital technologies in education: making new training experiences with teachers of basic education}

\section{Tecnologías digitales en la educación: tejiendo nuevas experiencias formativas con profesores de la educación básica}

Sandra Vírginia Correia de Andrade Santos ${ }^{2}$

Simone Lucena ${ }^{2}$

DOI: http://dx.doi.org/10.20435/serie-estudos.v24i51.1293

\begin{abstract}
Resumo: Os novos formatos de comunicação e interação, provocados principalmente pelo avanço das tecnologias digitais, têm adentrado nas inúmeras áreas do conhecimento, em especial, na Educação. Contudo, embora essas tecnologias tenham demonstrado potencialidades significativas, seu uso, em contextos educativos, permanece muitas vezes dissociado de um movimento pedagógico inovador e consistente, tendo em vista a continuidade de um ensino transmissivo e reprodutor. Diante disso, o presente artigo, fruto de uma pesquisa-formação em andamento, discute a formação permanente de professores como ponto de partida para a apropriação e fluência dos dispositivos digitais em contextos educativos, partindo do princípio de que, para o professor se reinventar, necessita de novas experiências formativas. Assim, a pesquisa tem como sujeitos professores de uma escola da rede pública, no município de Tobias Barreto, SE, os quais se encontram em um processo formativo mediado pelas tecnologias digitais e instituído pelos/com os próprios sujeitos. Portanto tem-se como resultados preliminares dilemas docentes que precisam ser contemplados nos processos formativos possibilitando vivências outras que potencializem a inserção das tecnologias digitais em sala de aula.
\end{abstract}

Palavras-chave: formação de professores; políticas públicas; tecnologias digitais.

\footnotetext{
${ }^{1}$ Este artigo é fruto de uma pesquisa desenvolvida no âmbito do Programa de Estímulo a Mobilidade e ao Aumento da Cooperação Acadêmica da Pós-Graduação em Sergipe - EDITAL CAPES/FAPITEC/ SE n. 10/2016.

${ }^{2}$ Universidade Federal de Sergipe (UFS), São Cristóvão, Sergipe, Brasil.
} 


\begin{abstract}
The new formats of communication and interaction, especially provoked by the advance of digital technologies, has penetrated countless areas of knowledge, especially Education. However, although these technologies have demonstrated significant potentialities, their use in educational contexts often remains dissociated from an innovative and consistent pedagogical movement, as the transmissive and reproductive education lasts. This article, the result of a research-training still in progress, discusses thepermanent formation of teachers as a starting point for the appropriation and influence of digital devices in educational contexts, assuming that, for the teachers to reinvent themselves, they need new formative experiences. For this reason, the research has as subjects teachers of a public school in the municipality of Tobias Barreto, SE, which are in a formative process mediated by digital technologies and instituted by/with the subjects themselves. Therefore, preliminary results are dilemmas that need to be contemplated in the training processes, enabling other experiences that enhance the insertion of digital technologies in the classroom.
\end{abstract}

Keywords: teacher training; public policy; digital technologies.

Resumen: Los nuevos formatos de comunicación e interacción, despertados principalmente por el progreso de las tecnologías digitales, han entrado en las numerosas áreas del conocimiento, em especial, en Educación. Sin embargo, aunque estas tecnologías han demostrado un potencial significativo, su uso, en contextos educativos, muchas veces, permanece desconectado de un movimiento pedagógico innovador y consistente, con vistas a la continuidad de una enseñanza transmisora y reproductora. Em vista de esto, este artículo, fruto de una investigación-formación, aún en curso, aborda la formación continua del profesorado como punto de partida para la apropiación y fluidez de los dispositivos digitales en contextos educativos, partiendo del principio de que, para que el profesor pueda reinventarse a sí mismo, necesita nuevas experiencias formativas. Así, la investigación tiene como sujetos profesores de una escuela de la red pública, en el municipio de Tobias Barreto-SE, los cuales se encuentran en un proceso formativo mediado por las tecnologías digitales e instituido por los / con los propios sujetos. Por lo tanto, se tienen como resultados preliminares dilemas docentes que necesitan ser contemplados en los procesos formativos posibilitando experiencias otras que potencien la inserción de las tecnologías digitales en el aula.

Palabras clave: formación de profesores; políticas públicas; tecnologías digitales.

\title{
1 INTRODUÇÃO
}

A educação brasileira vem sofrendo várias críticas nos últimos anos, nos mais variados aspectos. Dentre os aspectos apontados como frágeis, têm-se as questões infraestruturais, o baixo desempenho dos alunos, o alto índice de repetência e desistência, algumas lacunas na formação inicial e continuada dos professores e a falta de inovação no contexto da sala de aula. Contudo, embora sejam pontos distintos, apresentam uma relação cíclica de causa e consequência como, por exemplo, o fato de as lacunas formativas acarretarem o desenvolvimento de práticas docentes ineficazes e insuficientes acaba comprometendo o desempenho dos alunos, os quais, fatalmente, adentram nos índices de baixo desempenho, 
repetência ou desistência. Esse pensamento destaca quão importante é refletir sobre as problemáticas apontadas em busca de alternativas para que a educação brasileira se reinvente e avance.

Em contrapartida, acerca dessa temática, tornam-se indispensáveis reflexões e compreensões a respeito das transformações sociais que vêm ocorrendo, especialmente no campo tecnológico, as quais têm modificado as perspectivas dos sujeitos que se encontram em vários espaços sociais, inclusive na sala de aula. Tais transformações têm fomentado na educação a necessidade de ressignificar tanto os processos de ensino quanto os de aprendizagem, não por modismo, mas por acreditar que, para construir novas aprendizagens, são necessários movimentos didático-pedagógicos plurais. Nesse contexto, emergem as tecnologias digitais, dispositivos que potencializam, flexibilizam e ampliam os processos de ensino e de aprendizagem, contribuindo, portanto, para o reinventar das práticas em sala de aula. No entanto a efetivação do seu uso na Educação ainda não se encontra tão expressiva e consistente, apontando para a necessidade de uma formação docente que não só promova a inclusão digital dos professores, mas a sua "emancipação digital" (BACKES; SCHLEMMER, 2014).

Por conseguinte várias políticas públicas no Brasil propõem e garantem a inserção dessas tecnologias na educação básica, bem como o estímulo ao seu uso e à preparação por parte dos professores. Por outro lado, as formações ainda não deram conta de promover o uso efetivo e inovador desses dispositivos, uma vez que se entende como inovador as alterações de ideias, concepções, práticas renovadas em uma outra direção da já existente (GONZÁLEZ; ESCUDERO, 1987, p. 68). Em contextos educativos, portanto, exige-se não só uma fluência tecnológica, mas também a convergência de outros saberes e processos. Todavia, embora seja raro encontrar professores que não se sintam digitais e que não manuseiam seus dispositivos tecnológicos nas suas práticas cotidianas, em sala de aula esse uso não se apresenta com a dinamicidade própria que o digital contempla, pois sua presença permanece em uma perspectiva apenas instrumental e transmissiva do saber. Vivenciar as tecnologias digitais em situações de aprendizagem requer novas concepções e abordagens, pois essas tecnologias operam com outras lógicas abertas, colaborativas e interativas que não são comuns na perceptiva da educação centrada no ensino de conteúdos predefinidos. Diante disso, a formação docente precisa também ser (re)pensada, promovendo novas perspectivas de ensino em 
um espaço de convivência que integra as tecnologias à sua própria formação e atuação (IMBÉRNON, 2009).

Sendo assim, em uma sociedade em rede, constituída e potencializada pela era digital, é preciso promover contextos comunicativos e formativos que extrapolem a conexão tipicamente técnica, instrumental e inconsciente, pois essa permanência apenas solidifica um pensamento automático, seja ele de ideias, seja de atitudes. Nessa perspectiva, é necessário refletir que o digital, ao adentrar a Educação de modo significativo, tende a ampliar as conexões, interações, diálogos, trocas etc., uma vez que os professores precisam deixar de perceber as tecnologias apenas como ferramentas adicionais ou como instrumento para a motivação estudantil. As tecnologias digitais, nas práticas sociais, são formas de interação, de reconstruções sociais; em contextos educativos, também precisam se apropriar dessa cultura e promover redes de construção do conhecimento de modo ativo e reflexivo, colaborando para a formação de alunos protagonistas da sua própria aprendizagem.

Destarte, os processos formativos que envolvem os professores devem ser fundantes de novas perspectivas atitudinais, de preferência participando ativamente e incorporando novas práticas. Em contrapartida, embora as políticas públicas apresentem e contemplem os princípios e diretrizes para que as tecnologias digitais façam parte do cotidiano das escolas, por que ainda não há uma apropriação por parte dos professores? Quais as dificuldades que impedem a adesão a novas formas de ensinar com as tecnologias? Esses questionamentos nos fazem refletir sobre outras possibilidades de experiências formativas de professores com as tecnologias digitais para além de treinamentos e oficinas pontuais e aligeiradas. Possibilidades formativas que possibilitem aos professores (re)pensarem suas práticas docentes com as tecnologias digitais a partir dos seus conhecimento e práticas culturais com estas tecnologias no seu cotidiano dentrofora da escola.

Para promover, portanto, as reflexões proposta por esta pesquisa, tem-se como sujeitos professores de um escola pública no município de Tobias Barreto, $\mathrm{SE}$, pelos/com os quais está sendo desenvolvida uma experiência formativa em que são discutidos, refletidos, compreendidos e planejados usos plurais das tecnologias digitais que adentram o vivido e o experienciando, pois não se trata de receber informações sobre estratégias prontas, mas compreendê-las de tal modo a construir novos processos, de modo reflexivo e fundante de novas maneiras de 
fazer (CERTEAU, 2011). Diante disso, esta pesquisa, ainda em desenvolvimento, fundamenta-se na perspectiva metodológica da pesquisa-formação (SANTOS, 2014), tendo em vista a propositura de se constituir um dispositivo formativo em contexto digital, cujo percurso permitirá vivenciar e entrelaçar reflexões não só dos sujeitos praticantes, mas também do próprio pesquisador, o qual, ao passo em que forma, também se forma (MACEDO, 2010).

As discussões aqui apresentadas se pautam na reflexão sobre a inserção das tecnologias digitais na Educação e a formação permanente de professores, aqueles que já se encontram imersos nas práticas de sala de aula e que, ao mesmo tempo em que se encontram motivados a aprender, a fazer uso das tecnologias na sua arte de ensinar, permanecem muitas vezes inseguros e resistentes. Diante disso, o presente trabalho parte inicialmente de algumas considerações sobre as políticas públicas que permeiam as tecnologias digitais na Educação, compreendendo a perspectiva de sua inserção e, em seguida, discorrendo sobre a formação docente com as tecnologias digitais, bem como alguns dilemas que vêm se revelando no percurso da formação instituída com os próprios professores.

\section{TECNOLOGIAS DIGITAIS E FORMAÇÃO DOCENTE: UM BREVE PANORAMA DAS POLÍTICAS PÚBLICAS}

Transformar a educação por meio da utilização das tecnologias da informação e comunicação tem sido uma das principais investiduras do Ministério da Educação nos últimos anos. Com o propósito de promover contribuições efetivas e significativas na qualidade do ensino, as políticas públicas fizeram surgir, nessa temática, inúmeros programas, dentre eles o Programa Nacional de Tecnologia Educacional (Prolnfo), instituído inicialmente pela Portaria n. 522, de 9 de abril de 1997. Posteriormente, esse programa é reestruturado por meio do Decreto n. 6.300 de 12 de dezembro de 2007, o qual dá início ao Proinfo Integrado, ampliando suas ações. Trata-se, na verdade, da primeira e principal política nacional envolvendo as tecnologias ${ }^{3}$ da informação e comunicação, com o propósito de

\footnotetext{
${ }^{3}$ À época da implantação do Proinfo, nomeavam-se Tecnologias da Informação e Comunicação (TIC). Ao longo do tempo outras tecnologias foram sendo desenvolvidas, saindo do analógico para o digital, surgindo, portanto, as Tecnologias Digitais da Informação e Comunicação (TDIC). Contudo, neste trabalho adotaremos apenas o termo tecnologias digitais (TD) como referência às mesmas TDIC.
} 
promover o uso pedagógico, tanto no nível fundamental quanto no médio, nas redes públicas municipal e estadual. Esse marco, a priori, concebe essas tecnologias enquanto recursos potencializadores das práticas educativas, tendo em vista seu poder dinâmico e transformador. No entanto, em relação às políticas públicas e aos processos formativos já efetivados pelas redes de ensino, percebe-se que:

No âmbito das políticas, destacam-se as críticas de desprofissionalização, precarização e aligeiramento da formação, bem como a frágil articulação entre a formação inicial, a formação continuada, a inserção profissional e as condições de trabalho, salário e carreira dos profissionais da educação. E, no âmbito das práticas formativas, no contexto da formação inicial e continuada, as críticas dizem respeito principalmente à frágil articulação entre teoria e prática, entre conhecimento específico e conhecimento pedagógico, entre universidades e escolas. (GATTI et al., 2019, p. 177).

Dentre algumas ações do Proinfo, como a inclusão digital e a distribuição de máquinas e equipamentos, a preocupação com a formação de professores também esteve presente. Ao instituir o Proinfo Integrado, por exemplo, foram ofertados cursos, tais como Introdução à Educação Digital, Tecnologias na Educação e Pedagogia de Projetos, os quais se utilizavam da plataforma e-proinfo, um ambiente colaborativo e de fácil acesso, para utilização dos professores participantes, juntamente com o tutor que acompanhava as turmas e desenvolvia os módulos das formações. Nesse mesmo período, surge também outro programa governamental, o Programa um Computador por Aluno (Prouca), estabelecido pela lei n. 12.249, de 14 de junho de 2010. Esse programa tinha como objetivo principal promover a inclusão digital dos professores para que conseguissem desenvolver suas práticas de sala de aula mediante a utilização de computadores portáteis.

Em 2017, o Decreto 9.204, de 23 de novembro de 2017, institui o Programa de Inovação Educação Conectada, o qual propõe apoiar especialmente a universalização do acesso à internet de alta velocidade e fomentar o uso pedagógico das tecnologias digitais. Em sua organização, o programa apresenta quatro dimensões: visão, formação, recursos educacionais e infraestrutura. Esses quatro enfoques se unem como forma de garantir a efetiva utilização das tecnologias de modo a possibilitar e potencializar o desenvolvimento de novas formas de ensinar e de aprender. Dentre os princípios do Programa de Inovação Educação Conectada, tem-se:

$[\ldots]$

V- autonomia de professores na adoção da tecnologia para a educação; 
VI- estímulo ao protagonismo do aluno;

VII- acesso à internet com qualidade e velocidade compatíveis com as necessidades de uso pedagógico dos professores e dos alunos;

VIII- amplo acesso a recursos educacionais digitais de qualidade; e IX-incentivo à formação de professores e gestores em práticas pedagógicas com tecnologia e para uso de tecnologia. (BRASIL, 2017).

Analisando brevemente esses cinco últimos princípios, nota-se que o mais recente investimento, em relação às tecnologias digitais na educação, traz em seus fundamentos novos elementos sobre a temática. Para essa discussão, destacam-se o incentivo à formação não só dos professores, mas também dos gestores, a autonomia docente e o estímulo ao protagonismo do aluno. Observa-se, portanto, que a nova proposta apresenta a possibilidade de se refletir sobre outros elementos relativos às tecnologias digitais, não envolvendo, portanto, apenas a figura do professor, uma vez que outros componentes também são importantes para a apropriação e efetividade do uso das tecnologias na educação. Nesse caso, portanto, não só o professor será estimulado a fazer uso das tecnologias digitais, mas também o gestor escolar precisará passar pelo processo formativo, com o objetivo de compreender a realidade da escola e a importância da utilização de tais dispositivos nas práticas de sala de aula, evitando assim conflitos e, inclusive, proibições, como ocorre em alguns estabelecimentos de ensino. Desse modo, concebe-se na figura do gestor, um importante agente para que a adoção e o desenvolvimento das tecnologias na educação aconteçam e se consolidem. Por exemplo, é muito comum encontrarmos em espaços educativos professores que se predispõem a investir na sua formação e no desenvolvimento de novas práticas por meio dos dispositivos tecnológicos, entretanto encontram barreiras impostas pela própria gestão, justamente por não compreender o potencial pedagógico das tecnologias digitais, percebendo-a apenas enquanto uma distração para o aluno (essa visão simplista também é identificada em muitos professores).

Contemporaneamente, utilizar-se das tecnologias digitais em sala de aula é considerado uma inovação. A partir dessa percepção, acredita-se que o fato de equipar as escolas e ofertar periodicamente cursos de formação que possibilitem o domínio técnico-funcional das tecnologias seja garantia para inovar e desenvolver novas aprendizagens. No entanto, na prática, o que acontece é apenas a substituição de uma tecnologia por outra. Boa parte dos professores que buscam fazer uso dos dispositivos tecnológicos nas suas práticas de sala de 
aula não conseguem ultrapassar a transmissão de conteúdos. Na verdade, as tecnologias acabam sendo simplesmente um recurso novo, tendo em vista que os processos adotados continuam conservadores e mecânicos. A exemplo, tem-se o uso constante do datashow conectado a computadores ou notebooks, utilizados para projetar as aulas preparadas (em boa parte baixados da internet) para posterior apresentação dos conteúdos. Nesse formato de abordagem, o aluno permanece passivo e receptor de informação, característica principal de práticas que já demonstraram ineficiência. Não se trata aqui de críticas ao professor nem ao recurso, mas uma reflexão de como se dá esse processo em sala de aula e se, de fato, consolidam aprendizagens.

Outrossim, apesar de as políticas públicas apresentarem a proposta de fomentar a utilização das tecnologias digitais na educação, não deixam claro como isso se dará nem qual a perspectiva da formação para esse fim. Esse fato, portanto, traz para a centralidade da discussão como ocorre a formação dos professores no tocante às tecnologias digitais e, inclusive, como essas tecnologias passam a ser inseridas nas práticas de sala de aula durante e após as formações. Nesse sentido, acredita-se que, se para o Programa de Inovação Educação Conectada a autonomia da adoção por parte dos professores e o desenvolvimento do protagonismo estudantil são princípios fundantes, a formação docente precisa estar alinhada ao desenvolvimento de pensamentos, discussões e atitudes capazes de desenvolver essa autonomia e o protagonismo. Na verdade, promover a autonomia do docente também é algo limitante, uma vez que já acontece, pois as escolhas já são feitas pelo próprio professor. O que se necessita de fato é uma autonomia emancipadora dos processos mecanizados, aqueles cujo perfil solidifica ainda mais a transmissão do conhecimento. Por conseguinte, para que essas e outras ressignificações aconteçam e, inclusive, para que o conhecimento seja de fato construído, o processo formativo do professor necessita contemplar a sua vivência, suas experiências, anseios e potencialidades, estabelecendo diálogos e interconexões que se converterão em novas perspectivas de ensino e que, consequentemente, contribuirão para a constituição de novas identidades docentes e de resultados muito mais consistentes.

[...] não basta pensar a formação continuada de professores implementada por programas padronizados que estabelecem, a priori, as suas necessidades formativas, sem levar em consideração o que pensam os próprios professo- 
res e, tampouco, sem avaliar os seus impactos na prática dos professores. É preciso visualizar a formação continuada de professores como um espaço constituído por diversas ideologias, concepções, crenças, práticas e o próprio contexto escolar. (SANTOS, 2015, p. 48).

Portanto, abre-se a possibilidade de se constituir uma nova epistemologia de formação docente, tendo em vista que culturalmente são encontradas formações numa perspectiva pontual em forma de treinamento, minicurso ou oficina e aligeirada, muitas vezes dedicada tão simplesmente ao aprofundamento técnico e não promotores de novos saberes. Para Tardif (2014, p. 16), "os saberes de um professor são uma realidade social materializada através de uma formação, de programas, das práticas coletivas, de disciplinas escolares, de uma pedagogia institucionalizada etc., e são também, ao mesmo tempo os saberes dele", ou seja, a trajetória docente é permeada pela complexidade da sua formação e da sua atuação, a qual envolve os pressupostos e saberes que necessitam se distanciar da fragmentação ainda tão presente e marcante nos espaços educativos (MORIN, 2000).

Reconhecer a complexidade do pensamento e da prática docente significa aceitar que a educação, como fenômeno social, é uma rede aberta; que essa abertura faz com que, às vezes, se tomem decisões sem reflexão prévia, de forma intuitiva; que promover uma formação que facilita a reflexão e a intuição pode fazer com que os professores sejam melhores planejadores e gestores do ensino-aprendizagem e, por que não, agentes sociais, que podem intervir, além disso, nos complexos sistemas éticos e políticos da estrutura social e laboral. (IMBERNÓN, 2010, p. 101).

Por fim, busca-se constituir percursos formativos permanentes alinhados com o cotidiano escolar vivenciado pelos professores e alunos, de modo a não só demonstrar ideias, mas constituir novos processos, os quais possibilitarão uma apropriação pedagógica legítima e consolidada, tendo em vista que "faltam conhecimentos que possibilitem aos professores significar o uso dessas tecnologias a fim de propiciar desenvolvimento humano e social" (BACKES; SCHLEMMER, 2014, p. 1). Nesse sentido, compreende-se que as políticas públicas precisam avançar em suas propostas, garantindo principalmente o desenvolvimento de formações numa perspectiva processual em que se convergem saberes, os quais contribuem para a transformação dos sujeitos e de suas práticas em sala de aula. 


\section{REFLEXÕES SOBRE A FORMAÇÃO DE PROFESSORES}

As mudanças sociais e o surgimento de novos artefatos culturais ocorridas ao longo do tempo revelam, na contemporaneidade, o surgimento de novas formas de pensar e de agir, ou seja, diferentes formas de perceber e de atuar no mundo, bem como de interagir com as pessoas. No contexto educativo, essas transformações também se fazem presentes, o que leva a novas exigências tanto no tocante à prática de sala de aula quanto nos resultados obtidos. Nessa perspectiva, exige-se ressignificações pedagógicas que buscam cada vez mais se distanciar da perspectiva transmissiva do ensino para uma abordagem que promova a aquisição autônoma e autocrítica, bem como da sua relação com o outro em um processo dialógico, coletivo e colaborativo, levando o sujeito à construção de novos conhecimentos.

A prática pedagógica passa a ser exigida sob o aspecto da reflexão, da coletividade; o ato pedagógico demanda por uma intencionalidade, por meio da participação de todos, onde a colaboração com o outro leva a novas descobertas e a novas atitudes, promovendo a vontade de aprender e a vontade de ensinar, de modo legítimo para todos os envolvidos no processo. (CARPIM, 2014, p. 78).

Diante disso, questões como o papel do professor e da escola voltam à discussão em busca de compreender, de fato, a função de cada um no tocante à promoção do conhecimento, contribuindo para um redesenho do cenário educacional, o qual se apresenta com novas exigências e demandas pertencentes à contemporaneidade e ao próprio cotidiano escolar. Essa reflexão tem se intensificado cada vez mais, principalmente pela presença das tecnologias digitais em contextos educativos, tendo em vista as possibilidades de, com o seu uso, potencializar novas práticas de modo a oportunizar ressignificações a partir de sua multiplicidade processual que, dentre outras possibilidades, contribuem para o desenvolvimento de novos saberes.

[...] os saberes profissionais são variados e heterogêneos porque os professores, na ação, no trabalho, procuram atingir diferentes tipos de objetivos cuja realização não exige os mesmos tipos de conhecimento, de competência ou de aptidão. Dizendo de outra maneira, a prática profissional dos professores é heterogênea ou heterônima no tocante aos objetivos internos da ação e aos saberes mobilizados. (TARDIF, 2014, p. 263). 
Por conseguinte, a escola e os professores têm a missão de criar situações de aprendizagem, ou melhor, criar ambientes propícios à aprendizagem. Quando se fala em ambiente propício não é tão simplesmente adquirir e garantir o uso de equipamentos e mobiliários, mas gerenciar procedimentos em uma nova concepção de ensino e de aprendizagem. Reforça-se, entretanto, que o novo aqui é a busca por caminhos diferentes, de modo a "incorporar algo novo que resulte em melhoria no âmbito da instituição escolar, em suas estruturas e processos, visando ao êxito de sua função social" (FARIAS, 2006, p. 36).

A partir dessa perspectiva, portanto, destaca-se a necessidade de uma travessia da visão transmissiva de ensino, seguida por processos mecânicos e inflexíveis, para uma abordagem plural, crítica, reflexiva e construtora, em que se experienciam ativamente os conceitos, os problemas, as relações de sentido etc. Isso leva, a priori, ao redimensionamento das práticas pedagógicas e à dinamização dos processos, integrando novas ideias e procedimentos ao que já se encontra consolidado, confabulando com sua natureza complexa, já que a Educação “implica simultaneamente conservação (dos dados do saber adquirido) e criação, ou seja, crítica, negação e substituição do saber existente" (PINTO, 1994, p. 34), fazendo emergir um dos maiores desafios educacionais: a inovação. Assim, com base nessa problemática, percebe-se que há na verdade dois desafios envolvendo os professores: a apropriação dos dispositivos tecnológicos e a inserção de uma nova abordagem pedagógica. Assevera-se aqui que esses desafios não devem ser vistos dissociáveis, pois é a convergência dos saberes que possibilitam a construção de um ambiente educativo novo, desafiante, reflexivo e de descobertas.

O fato é que, para que haja a 'revolução' pedagógica, direcionada ao desenvolvimento dos alunos, a partir da convergência dos saberes técnicos, didáticos e pedagógicos, tem-se a formação dos professores como ponto de partida, uma formação que desenvolva saberes tanto no campo teórico quanto no prático. Isso nos faz pensar sobre, como já fora dito, novas diretrizes para a formação de professores com as tecnologias digitais, uma vez que, embora as políticas públicas tenham garantido legalmente o fomento à formação dos professores, nota-se que as realizações ainda não consolidaram novos saberes nem a capacidade autônoma e plural do docente, tendo em vista que, ao passo em que os cursos vão sendo concluídos, as TD vão deixando de fazer parte de suas práticas de sala de aula ou se cristalizam mecanicamente. 
Essa lacuna ainda presente na transição entre a formação e a aplicabilidade no cotidiano da escola nos faz pensar em como se dera esse percurso formativo, na tentativa de encontrar alternativas que auxiliem e contribuam para não só pensar sobre as tecnologias, mas também pensar com, pois se acredita que, desse modo, os professores passarão a compreender melhor os processos, e não simplesmente se basearem em procedimentos adotados por outros. Com esse redesenho formativo, acredita-se que a autonomia e a flexibilidade dos usos se consolidarão. Ao sinalizar que é necessário pensar com e não apenas sobre as tecnologias, empreende-se uma perspectiva formativa que integra os dispositivos tecnológicos ao próprio processo de formação, desconectando a ideia de que as tecnologias são apenas objetos sobre os quais precisamos aprender, pois, no contato direto, no manuseio, na compreensão de suas possibilidades, é que a apropriação acontece.

Nesse sentido, a revolução que precisa ser feita é que cada docente se sinta capaz de construir seus processos compreendendo não só o que está fazendo, mas também quais as aprendizagens que está proporcionando aos alunos. Muitas vezes esquece-se que os professores, em formação, encontram-se na mesma condição de alunos: em processo de aprendizagem. E, enquanto alunos, também necessitam aprofundar seus conhecimentos sobre e com o que está se relacionando, proporcionando uma imersão capaz de promover novas descobertas. Essa (auto)reflexão incentiva o professor a repensar o seu 'modelo' de ensino, tornando-se capaz de identificar as possíveis lacunas e os possíveis novos caminhos, distanciando-se cada vez mais da perspectiva de ensinar tudo pronto o tempo todo e para todo o tempo. Nota-se, contudo, que ainda persiste em vários espaços educativos o modelo de ensino transmissivo, em que o professor 'apostila' o conhecimento e o deposita na memória do aluno, numa educação bancária, definida por Paulo Freire, tendo em vista que, na maioria das vezes, o professor extrai o que acredita ser mais importante e apenas repassa ao aluno, o qual a recebe ao invés de descobri-la.

Em meio a essa realidade, percebe-se que a formação permanente de professores ao ter como foco conhecer modelos aplicáveis em sala de aula não promove a apropriação pedagógica dos dispositivos tecnológicos. Trata-se de uma abordagem reprodutiva e limitante. Refletir sobre sua área de ensino e sobre a aprendizagem, compreendendo como ela acontece no contexto da sala de aula, 
é tão importante quanto compreender os procedimentos, uma vez que "a ação de ensinar exige uma formação específica, o pleno domínio do conhecimento teórico e da realidade prática da profissão" (FERREIRA, 2014, p. 38). Portanto, ao passo em que os professores refletem sobre como "darão a sua aula", esse pensamento não deve ser aleatório, mas alinhado a princípios, os quais revelam os meios mais eficazes de produzir conhecimento e isso se aplica também às variadas tecnologias digitais.

De fato, compreender o caminho sistemático e dialógico que permeia a prática docente contribui para que os processos sejam capazes de projetar novas aprendizagens. Nesse contexto, o professor se torna o mediador da aprendizagem, ressignificando, portanto, não só o seu ensinar, mas o aprender do aluno. Desse modo, conceber a formação continuada dos professores como uma reconstrução permanente, imersa na cultura escolar e fortalecida pelas interações e discussões entre os sujeitos participantes e fundantes de práticas educativas, coloca os docentes enquanto protagonista do próprio processo formativo, uma vez que a mediação (instrumental ou simbólica) é um importante processo inerente à prática educativa, pois "é pela mediação que se dá a internalização (reconstrução interna) de uma operação externa de atividades e comportamentos sócio-históricos e culturais" (GASTON, 1992, p. 89, citado por MOREIRA, 1999, p. 110).

Vale ressaltar que uma formação docente em que oportunize aos professores uma percepção convergente entre a teoria e a prática, mergulhado em seu contexto de atuação e tornando possível uma reconstrução, uma transformação da sua experiência em novo conhecimento, permitirá se reinventar e, assim, tecer aprendizagens suas e de seus alunos. Com esse pensamento, defende-se a ideia de que a própria experiência docente faz parte da sua formação profissional, pois é durante sua atuação que o docente converge teoria e prática.

A formação de professores é uma ação contínua e progressiva que envolve várias instâncias, e atribui uma valorização significativa para a prática pedagógica, para a experiência, como componente constitutivo da formação. Ao valorizar a prática como componente formador, em nenhum momento assume-se a visão de dicotomia da relação teoria-prática. (VEIGA, 2009, p. 27).

Evidencia-se ainda que esse processo reflexivo se configura enquanto complexo, pois corrobora para a compreensão e não tão simplesmente a execução, ampliando, assim, o individual e o coletivo, uma vez que são momentos em que 
se aprende consigo e com o outro, instituindo redes de experiências docentes que não se encerram nos espaços formativos, pois "o saber não é isolado, ele é partiIhado e transforma-se, modifica-se a partir da troca de experiências e da reflexão coletiva com os outros" (SANTOS, 2015, p. 26), ou seja, o saber estabelece-se por meio de parcerias e de engajamento estimulado pela própria atividade de investigação na qual o ensino fundamenta-se, ocasionando experiências significativas.

Sendo assim, apropriar-se de novas formas de uso das TD para além da instrumentalização requer uma formação instituída numa perspectiva de descobertas e compreensões, estimulando a ressignificação das práticas, não por ser uma exigência externa, mas por se acreditar que, como as mudanças sociais aconteceram, a sala de aula reflete a necessidade de mudanças processuais também, pois novos sujeitos se encontram presentes. Esse fato tem gerado cada vez mais a necessidade de se reinventar e compreender que ensinar transcende a transmissão de conteúdo.

\section{TECENDO PROCESSOS FORMATIVOS COM OS PROFESSORES}

Para o desenvolvimento da pesquisa, foi escolhida uma escola pública no município de Tobias Barreto, SE, a qual, além de ter sido contemplada em 2008 com o laboratório de informática, por meio do Programa Nacional de Tecnologia Educacional (Proinfo), fora também o espaço onde ocorreram as primeiras formações dos professores no tocante à utilização das tecnologias em práticas educativas. Essas formações ocorreram entre os anos de 2009 e 2011, tendo como participantes tanto os professores desta escola quanto das demais pertencentes à rede municipal de ensino. A escola fica localizada nas proximidades do centro comercial da cidade e atende a 1363 alunos, distribuídos nos três turnos. Para atendimento a essa clientela, conta com aproximadamente 56 professores, sendo todos licenciados em Pedagogia ou na área de atuação, salvo algumas exceções para complemento de carga horária.

Do total de professores que atuam nessa escola, 52,2\% já participaram de formação envolvendo as tecnologias digitais em sala de aula, e 60,8\% usam tecnologias nas aulas para introduzir um assunto ou revisá-lo, por meio principalmente do datashow, prevalecendo, assim, uma abordagem expositiva, demonstrando também que este uso é o mais recorrente nas práticas de sala de aula, tanto por professores que já participaram de processos formativos, quanto para os que 
ainda não tiveram esse tipo de experiência com as TD. Por outro lado, 21,7\% dos professores relataram fazer uso dessas tecnologias com os alunos, numa perspectiva mais ativa do ensino em que os próprios alunos desenvolvem suas aprendizagens por meio dos dispositivos digitais, com os quais realizam entrevistas, gravam vídeos, acessam aplicativos, dentre outras situações.

Portanto o fato de boa parte dos professores, sujeitos da pesquisa, já terem passado por formações envolvendo as tecnologias digitais em sala de aula e, também, por fazerem uso em suas práticas de sala de aula possibilita reflexões importantes sobre a formação na perspectiva da formação permanente e em serviço. Assim, ao estarem em efetiva atuação e buscarem integrar os dispositivos tecnológicos em suas práticas, os professores acabam externalizando, durante os processos formativos, seus dilemas digitais, evidenciando especialmente dois pontos conflitantes: enquanto de um lado têm a concepção de que os dispositivos digitais potencializam as práticas de sala de aula, do outro, a maioria propaga a crença de que não dominam as tecnologias contemporâneas, o que contribui para a não inserção desses dispositivos no cotidiano escolar. Ou seja, apesar de considerarem importante a utilização das tecnologias, são poucos os que as utilizam em suas aulas para além da exposição de conteúdos, o que nos leva a refletir sobre os processos formativos e as possíveis lacunas que acompanham tais processos.

Talvez seja porque ainda predominem políticas e formadores que praticam com afinco e entusiasmo uma formação transmissora e uniforme, com um predomínio de uma teoria descontextualizada, válida para todos, estejam onde estiveres, distante dos problemas práticos reais, com base num professor médio que não existe. (IMBERNÓN, 2009, p. 34-5).

Esse fato é ainda mais evidenciado e potencializado pela constante autoclassificação presente na fala de muitos professores, a de que são "analfabetos digitais" ${ }^{\prime 4}$. De certa forma, o fato de se considerarem desconhecedores faz emergir o interesse em participar de processos formativos para que se apropriem dos dispositivos e desenvolvam sua autoconfiança. No entanto, em muitos momentos

\footnotetext{
${ }^{4}$ Os professores, sujeitos da pesquisa, constantemente se declaram analfabetos digitais, mesmo fazendo uso cotidianamente dos dispositivos digitais. Esse sentimento se dá principalmente pela comparação que fazem com os seus alunos, os quais, segundo os professores, dominam as tecnologias contemporâneas.
} 
essa autoclassificação negativiza o processo de aprender, gerando limitações e insegurança por parte dos professores, os quais acabam desacreditando que o domínio é possível.

Diante dessa realidade, entretanto, ressalta-se que desenvolver uma formação de professores pressupõe compreender as suas problemáticas e traçar possibilidades de resolvê-las em diálogo, reflexões e decisões, estimulando não só a apropriação dos dispositivos, mas a compreensão de percursos metodológicos significativos. Ou seja, para que as TD não sejam uma simples ferramenta para execução de tarefas, mas sim um dispositivo que potencializa aprendizagens, é necessário experimentá-las em processos reais de linguagem, interação, construção do saber e de forma não aligeirada, ou seja, em uma "formação permanente mais adequada, acompanhada pelo apoio necessário durante o tempo que for preciso" (IMBERNÓN, 2009, p. 30).

Assim, refletir sobre como as TD são utilizadas pelos professores em contextos educativos e quais suas expectativas em participar de processos formativos no tocante ao uso dessas tecnologias leva a indagações que permeiam esta pesquisa ainda em andamento. Compreender, portanto, os processos já existentes fora o ponto de partida para refletir sobre a formação de professores, buscando desenhar um processo que promovesse descobertas e que mobilizasse saberes, superando os processos mecânicos cristalizados, tanto do ponto de vista da formação docente, quanto da inserção dos dispositivos digitais, "uma vez que os caminhos formativos se definem mediante a condução dos conhecimentos de senso comum preexistentes aos conhecimentos fundamentados que sustentam práticas pedagógicas" (GATTI et al., 2019, p.40-1). Assim, trata-se de buscar uma formação que delineie novas diretrizes formativas e que proponha integrar os dispositivos digitais ao próprio processo de formação, num movimento em que se pensa com as tecnologias, experienciando e compreendendo suas possibilidades e potencialidades didático-pedagógicas, bem como refletindo sobre a realidade contemporânea.

Ao discutir-se formação de professores para a educação básica é importante que se tenha um referencial sobre o papel da educação básica escolar na sociedade contemporânea o qual tem a função de orientar e dar sentido para as escolhas formativas relativas a esse profissional da educação. (GATTI et al., 2019, p. 34). 
Nesse contexto, como proposta desta pesquisa, buscou-se constituir um dispositivo formativo junto aos professores, alinhando todo o processo às demandas dos próprios docentes para que o vivido-aprendido passasse a ser aprendido-vivido, ou seja, que a formação não seja um processo que acabe em si, que se finalize quando os encontros deixarem de existir, mas que contribua para que os docentes tracem seus novos caminhos a partir da sua realidade e de suas possibilidades, as quais precisam ser pensadas, refletidas, compreendidas e, por fim, ressignificadas.

Sendo assim, a partir de uma reunião na escola, apresentamos a proposta de formação e convidamos os professores que tivessem interesse tanto na formação quanto na contribuição para a pesquisa. A partir desse momento, foram disponibilizados dois formulários online, o primeiro na perspectiva da formação e atuação docente e o segundo para compreensão das tecnologias que já fazem parte do seu dia a dia e também de suas práticas de sala de aula. A partir do levantamento dos dados produzidos, foram realizados na escola dois encontros iniciais com os professores para socialização das informações obtidas, bem como desenhar coletivamente o percurso formativo, atendendo à sua realidade e anseios.

Ao discutirmos com os professores os pontos que emergiram de suas respostas, foi possível traçarmos juntos a organização temática da formação, a qual se tornou indispensável para composição processual do dispositivo, uma vez que se trata, sobretudo, de um percurso formativo que garante não só a inserção das tecnologias digitais em práticas educativas, mas especialmente o sentimento de pertencimento dos professores, criando, portanto, condições favoráveis para o seu envolvimento ativo e significativo. Assim, com a identificação das percepções docentes em relação às tecnologias em práticas educativas, foi possível a construção dos módulos temáticos. A priori, reforça-se que se trata de uma organização inicial, uma vez que a formação proposta se alicerça nos princípios da flexibilidade, do diálogo e da construção coletiva e colaborativa e, desse modo, permitirá possíveis alterações em meio às experiências e reflexões realizadas. Com base nesses princípios, fora constituída a seguinte organização: 
Quadro 1 - Módulos que compõem o dispositivo formativo

\begin{tabular}{|l|l|}
\hline Módulo 1 & Tecnologias digitais e suas possibilidades multimodais \\
\hline Módulo 2 & O app-learning: o que é? Como desenvolver? \\
\hline Módulo 3 & O podcast e seu potencial linguístico \\
\hline Módulo 4 & A gamificação e o processo de criação e utilização \\
\hline Módulo 5 & A produção de slides criativos \\
\hline Módulo 6 & O vídeo: um produto audiovisual \\
\hline Módulo 7 & Avaliando o processo formativo \\
\hline
\end{tabular}

Fonte: Elaborado pelas autoras.

Como se percebe, os módulos indicados no Quadro 1 contemplam uma organização temática plural, a qual apresenta várias possibilidades de abordagem nas práticas de sala de aula por meio de artefatos digitais também plurais. Proporcionar diálogos entre esses artefatos, os conteúdos e os objetivos didáticos será o ponto fundante das experiências que se pretende desenvolver durante o percurso formativo, possibilitando que os professores vivenciem ativamente, autorizando-se e construindo seus etnométodos (MACEDO, 2006), uma vez que, nas falas docentes, já se evidencia a expectativa de se autorizar, ou seja, de ser autor dos seus próprios processos e produtos, com autonomia e inovação. De fato, a vivência em sala de aula nos faz pulsar continuamente o desejo pelo novo, pelas novas maneiras de fazer. E é a partir dessa concepção que o dispositivo formativo se propõe, não simplesmente para atendimento da pesquisa, mas para construir novas possibilidades em sala de aula, enriquecendo as aprendizagens docentes e discentes.

\section{ALGUMAS CONSIDERAÇÕES}

A transformação educacional parte da mudança de paradigmas, por meio de situações em contínuo diálogo com o real e os sentidos, permitindo a exploração e não apenas a recepção do conhecimento. Para isso, a formação no tocante às tecnologias digitais precisa ser situada no contexto em que os professores e alunos estão inseridos, entrelaçando reflexões pensadas ou reconstruídas em um processo contínuo e interativo. A partir desses aspectos, tem-se uma formação que tem como pilares a imersão, a interação e a (auto)reflexão. Não se trata, entretanto, apenas de formar para o uso das tecnologias, mas aprender com elas, 
possibilitando que se assuma o comando da sua aprendizagem, fomentando, por exemplo, a elaboração de hipóteses, a criação de estratégias e a construção de conceitos e significações.

Desse modo, embora as políticas públicas garantam o livre acesso aos equipamentos e aos movimentos em rede, o fomento à formação docente e à inserção das tecnologias digitais nas práticas de sala de aula traz benefícios somente quando vêm em uma perspectiva que vai se constituindo numa apropriação contínua e cada vez mais criativa, produzindo, assim, novas formas de conhecer, de refletir e de agir. Essa progressão transformativa contribui para uma nova lógica de ensinar, a qual sai do campo da instrumentalização das TD para a incorporação de processos potencializadores de aprendizagens, em um movimento sempre desafiante e reconfigurado.

Assim, a presente pesquisa considera que integrar as tecnologias digitais em contextos educativos demanda experiências formativas permanentes e tecidas a partir da realidade docente, as quais necessitam, dentre outros encaminhamentos, possibilitar a convergência de saberes indispensáveis à sua emancipação digital e, consequentemente, à construção de novas formas de ensinar e de aprender, trazendo, portanto, contribuições significativas para a educação.

\section{REFERÊNCIAS}

BACKES, Luciana; SCHLEMMER, Eliane. O processo de aprendizagem em metaverso: formação para emancipação digital. DESENVOLVE: Revista de Gestão do Unilasalle, Canoas, RS, v. 3, n. 1, p. 47-64, mar. 2014 Disponível em: https://revistas.unilasalle.edu.br/index. php/desenvolve/article/view/1387. Acesso em: 8 jan. 2019.

BRASIL. Decreto n. 9.204, de 24 de novembro de 2017. Institui o Programa de Inovação Educação Conectada e dá outras providências. Diário Oficial, Brasília, DF, 24 nov. 2017. Seção 1, p. 41.

CARPIM, Lucymara. Formação continuada e a prática pedagógica do professor universitário: um fazer colaborativo. In: FERREIRA, Jacques de Lima (Org.). Formação de professores: teoria e prática pedagógica. Petrópolis, RJ: Vozes, 2014.

CERTEAU, Michel de. A invenção do cotidiano: 1. Artes de fazer. Petropólis, RJ: Vozes, 2011.

FARIAS, Isabel Maria Sabino de. Inovação, mudança \& cultura docente. Brasília: Liber Livros, 2006. 
FERREIRA, Jacques de Lima. A complexa relação entre teoria e prática pedagógica na formação de professores. In: FERREIRA, Jacques de Lima (Org.). Formação de professores: teoria e prática pedagógica. Petrópolis, RJ: Vozes, 2014.

GATTI, Bernardete et al. Professores do Brasil: novos cenários de formação. Brasília: UNESCO, 2019.

GONZÁLEZ, Maria Tereza; ESCUDERO, Juan Manuel. Innovación educativa: teorías y procesos de desarrollo. Barcelona: Humanitas, 1987.

IMBERNÓN, Francisco. Formação continuada dos professores. Tradução de Juliana dos Santos Padilha. Porto Alegre, RS: Artmed, 2010.

IMBERNÓN, Francisco. Formação permanente do professorado: novas tendências. São Paulo: Cortez, 2009.

MACEDO, Roberto Sidnei. Etnopesquisa crítica, etnopesquisa-formação. Brasília: Liber Livro, 2010.

MOREIRA, Marco Antonio. Teorias de Aprendizagem. São Paulo: EPU, 1999.

MORIN, Edgar. Ciência com consciência. Rio de Janeiro: Bertrand, 2000.

PINTO, Alvaro Vieira. Sete lições sobre a educação de adultos. São Paulo: Cortez, 1994.

SANTOS, Edméa. Pesquisa-formação na cibercultura. Santo Tirso, Portugal: Whitebooks, 2014.

SANTOS, Aparecido dos. Formação de professores e as estruturas multiplicativas: reflexões teóricas e práticas. Curitiba: Appris, 2015.

TARDIF, Maurice. Saberes docentes e formação profissional. Petrópolis, RJ: Vozes, 2014 VEIGA, Ilma Passos Alencastro. A aventura de formar professores. Campinas, SP: Papirus, 2009. 


\section{Sobre as autoras:}

Sandra Vírginia Correia de Andrade Santos: Doutoranda em Educação pela Universidade Federal de Sergipe (UFS). Mestre em Letras (UFS). Especialista em Metodologia do Ensino de Língua Portuguesa e Literatura (Ages), Docência e Tutoria a Distância (UNIT), Tecnologias na Educação (PUC-Rio). Graduada em Letras (UFS). Professora das redes estadual e municipal no município de Tobias Barreto, SE. Membro do Grupo de Pesquisa Educação e Culturas Digitais (ECult/UFS/CNPq). E-mail: sanlitera@yahoo.com.br, Orcid: http://orcid.org/0000-0002-0129-056X

Simone Lucena: Pós-doutora em Educação pela Universidade do Estado do Rio de Janeiro (UERJ). Doutora em Educação pela Universidade Federal da Bahia (UFBA). Professora do Programa de Pós-graduação em Educação e do Departamento de Educação da Universidade Federal de Sergipe (UFS). Líder do Grupo de Pesquisa em Educação e Culturas Digitais (ECult/UFS/CNPq). E-mail: sissilucena@gmail.com, Orcid: http://orcid.org/0000-0003-1636-7707

Recebido em março de 2019 Aprovado em agosto de 2019 
